

\section{The new TNM classification of lung cancer in practice}

\section{Educational aims}

1 To describe the changes in the 7th edition of the TNM classification of lung cancer

1 To discuss the clinical implications of the incorporation of the new TNM classification in everyday practice

1 To emphasise the key points for a proper pathologic classification

\section{Summary}

The 7th edition of the TNM (tumour, node, metastases) classification of lung cancer incorporates the proposals of the International Association for the Study of Lung Cancer, whose database included more than 100,000 patients from Asia, Australia, Europe, and North America. The changes affect the Tand the M components of the classification, and the stage grouping. The $\mathrm{N}$ component remained unaltered, although the present descriptors were validated both in the clinical and pathologic settings. This new TNM classification applies to non-small cell lung cancer, small cell lung cancer and, for the first time, to broncho-pulmonary carcinoids. The innovations allow for a better separation of tumours with significantly different prognosis, and imply a more careful determination of tumour size.

\section{Introduction}

The 7th edition of the tumour, node and metastasis (TNM7) classification of lung cancer was officially enacted on January 1 , 2010, and applies to non-small cell and small cell carcinomas and to bronchopulmonary carcinoids (table 1) [1]. It incorporated the latest revision of the classification, which was based on the analyses of the International Association for the Study of Lung Cancer (IASLC) database. The IASLC database included 100,869 patients with lung cancer (table 2), of whom 81,495 fulfilled the inclusion criteria and were available for analyses [2]. The results of these analyses originated several proposals to modify the 6th edition of the TNM classification (TNM6). These proposals were published in the Journal of Thoracic Oncology [3-9], were internally and externally validated [10], were accepted by the International Union Against Cancer (UICC) and the American Joint Committee on Cancer (AJCC), and were eventually published in their respective staging manuals $[11,12]$. The TNM7 applies to non-small cell lung carcinomas, to small cell carcinomas $[7,8]$ and, for the first time, to bronchopulmonary carcinoids [9].

After more than one year of practical use, the innovations in the 7th edition have raised questions, the answers to which are not always easy. This review will emphasise the most relevant aspects of the introduction of the new TNM classification in clinical practice.
R. Rami-Porta

D.J. Giroux ${ }^{2}$

P. Goldstraw ${ }^{3}$

${ }^{1}$ Thoracic Surgery Service, Hospital Universitari Mutua Terrassa,

Terrassa, Barcelona, Spain

${ }^{2}$ Cancer Research And Biostatistics, Seattle, WA, USA

${ }^{3}$ Department of Thoracic Surgery, Royal Brompton Hospital and Imperial College, London, UK

Correspondence

R. Rami-Porta

Thoracic Surgery Service Hospital Universitari Mutua Terrassa

Plaza Dr. Robert 5

08221 Terrassa

Barcelona

Spain

rramip@yahoo.es

Competing interests None declared. 
Table 1. Seventh edition of the tumour, node and metastasis (TNM) classification of lung cancer

\begin{tabular}{|c|c|}
\hline $\begin{array}{l}\text { TNM components and } \\
\text { categories }\end{array}$ & Definitions \\
\hline \multicolumn{2}{|l|}{ T: Primary tumour } \\
\hline TX & $\begin{array}{l}\text { Primary tumour cannot be assessed; or tumour proven by the presence of malignant cells in sputum or bronchial } \\
\text { washings but not visualised by imaging or bronchoscopy }\end{array}$ \\
\hline TO & No evidence of primary tumour \\
\hline Tis & Carcinoma in situ \\
\hline $\mathrm{T} 1$ & $\begin{array}{l}\text { Tumour } \leqslant 3 \mathrm{~cm} \text { in greatest dimension, surrounded by lung or visceral pleura, without bronchoscopic evidence of } \\
\text { invasion more proximal than the lobar bronchus (i.e. not the main bronchus) }\end{array}$ \\
\hline T1a & Tumour $\leqslant 2 \mathrm{~cm}$ in greatest dimension \\
\hline $\mathrm{T} 1 \mathrm{~b}$ & Tumour $>2 \mathrm{~cm}$ but $\leqslant 3 \mathrm{~cm}$ in greatest dimension \\
\hline \multirow[t]{4}{*}{ T2 } & $\begin{array}{l}\text { Tumour }>3 \mathrm{~cm} \text { but } \leqslant 7 \mathrm{~cm} \text { or tumour with any of the following features (T2 tumours with these features are } \\
\text { classified T2a if } \leqslant 5 \mathrm{~cm} \text { ): }\end{array}$ \\
\hline & Involves main bronchus, $\geqslant 2 \mathrm{~cm}$ distal to the carina \\
\hline & Invades visceral pleura \\
\hline & $\begin{array}{l}\text { Associated with atelectasis or obstructive pneumonitis that extend to the hilar region but does not involve } \\
\text { the entire lung }\end{array}$ \\
\hline $\mathrm{T} 2 \mathrm{a}$ & Tumour $>3 \mathrm{~cm}$ but $\leqslant 5 \mathrm{~cm}$ in greatest dimension \\
\hline $\mathrm{T} 2 \mathrm{~b}$ & Tumour $>5 \mathrm{~cm}$ but $\leqslant 7 \mathrm{~cm}$ in greatest dimension \\
\hline T3 & $\begin{array}{l}\text { Tumour }>7 \mathrm{~cm} \text { or one that directly invades any of the following: chest wall (including superior sulcus tumours), } \\
\text { diaphragm, phrenic nerve, mediastinal pleura, parietal pericardium; or tumour in the main bronchus }<2 \mathrm{~cm} \\
\text { distal to the carina } \# \text { but without involvement of the carina; or associated atelectasis or obstructive pneumonitis } \\
\text { of the entire lung; or separate tumour nodule(s) in the same lobe }\end{array}$ \\
\hline T4 & $\begin{array}{l}\text { Tumour of any size that invades any of the following: mediastinum, heart, great vessels, trachea, recurrent } \\
\text { laryngeal nerve, oesophagus, vertebral body, carina; separate tumour nodule(s) in a different ipsilateral lobe }\end{array}$ \\
\hline \multicolumn{2}{|c|}{ N: Regional lymph nodes } \\
\hline NX & Regional lymph nodes cannot be assessed \\
\hline NO & No regional lymph node metastasis \\
\hline $\mathrm{N} 1$ & $\begin{array}{l}\text { Metastasis in ipsilateral peribronchial and/or ipsilateral hilar lymph nodes and intrapulmonary nodes, including } \\
\text { involvement by direct extension }\end{array}$ \\
\hline N2 & Metastasis in ipsilateral mediastinal and/or subcarinal lymph nodes \\
\hline N3 & $\begin{array}{l}\text { Metastasis in contralateral mediastinal, contralateral hilar, ipsilateral or contralateral scalene, or supraclavicular } \\
\text { lymph node(s) }\end{array}$ \\
\hline \multicolumn{2}{|l|}{ M: Distant metastasis } \\
\hline MO & No distant metastasis \\
\hline M1 & Distant metastasis \\
\hline M1a & $\begin{array}{l}\text { Separate tumour nodule(s) in a contralateral lobe; tumour with pleural nodules or malignant pleural (or } \\
\text { pericardial) effusion }\end{array}$ \\
\hline M1b & Distant metastasis \\
\hline
\end{tabular}

Changes in TNM descriptors and stages

\section{Measurement of the greatest tumour dimension}

Table 3 shows the changes introduced in the TNM7 compared with the TNM6. A look at the table shows that there are changes that demand more effort from us. All changes related to tumour size require precise measurements of the greatest tumour dimension. However, the remaining changes, those in the classification of additional tumour nodules, pleural dissemination, metastases and stages require only that we apply a different descriptor.

The identification of five tumour size groups with significantly different prognosis was first based on the selected population of patients with T1-T2 NO MO completely resected tumours 


\section{Table 2. Geographic distribution of patients with lung cancer submitted to the International Association for the Study of Lung Cancer database}

$\begin{array}{lr}\text { Continent } & \begin{array}{c}\text { Number of } \\ \text { patients }\end{array} \\ \text { Australia } & 9,416 \\ \text { Asia } & 11,622 \\ \text { North America } & 21,130 \\ \text { Europe } & 58,701 \\ \text { Total } & 100,869\end{array}$

who had received no induction therapy, but was also confirmed in patients with tumours with nodal disease, incomplete resection, and in those with clinically staged tumours $[3,10]$. To measure tumour size, the greatest dimension must be registered, but the TNM classification does not tell us how to measure it. Computed tomography (CT) is the most common imaging technique to study lung lesions, but in measuring tumour size several conditions may yield different measurements: a) window setting: for lung parenchyma or for mediastinum; b) projection: axial, sagittal or coronal; and c) breathing cycle: inspiration or expiration. In patients who also have positron emission tomography (PET) scans, the PET image may help define the tumour mass in an atelectatic lobe or lung and improve the precision of tumour size measurement. In any case, especially when multiple measurements are anticipated, as in those patients who will be treated with induction therapy and whose tumours will be measured before and after treatment to assess the objective tumour response, it is important to ensure consistency that all tumour size measure ments be carried out in the same conditions. The UICC recommends that one consult with the attending radiologist, who will know which window setting and which condition provide the most accurate measurement in one's institution [13].

\section{Clinical impact of additional tumour nodules}

The downstaging of T4 tumours by additional tumour nodule(s) in the same lobe of the primary tumour to $\mathrm{T} 3$, and of $M 1$ tumours by additional tumour nodule(s) in another ipsilateral lobe or lobes to T4 was based on differences in survival in pathologically staged tumours. There were fewer clinically staged tumours with these conditions, which reflects the difficulty to obtain histopathologic diagnosis in the clinical staging $[3,10]$, but the findings were consistent when the Surveillance, Epidemiology and End Results (SEER) database was analysed [10]. The IASLC database did not allow us to differentiate in these $\mathrm{T} 3$ and $\mathrm{T} 4$ conditions according to number or size of the additional tumour nodule(s). This raises prognostic and therapeutic doubts in clinical practice. One of these situations is described

\section{Table 3. Changes in the 7th edition of the tumour, node and metastases (TNM) classification of lung cancer compared with the 6th edition}

\begin{tabular}{|c|c|c|}
\hline Condition & Descriptor in 6 th edition & Descriptor in 7th edition \\
\hline Tumour size $\leqslant 2 \mathrm{~cm}$ & $\mathrm{~T} 1$ & T1a \\
\hline Tumour size $>2 \mathrm{~cm}$ but $\leqslant 3 \mathrm{~cm}$ & $\mathrm{~T} 1$ & $\mathrm{~T} 1 \mathrm{~b}$ \\
\hline Tumour size $>3 \mathrm{~cm}$ but $\leqslant 5 \mathrm{~cm}$ & T2 & T2a \\
\hline Tumour size $>5 \mathrm{~cm}$ but $\leqslant 7 \mathrm{~cm}$ & T2 & $\mathrm{T} 2 \mathrm{~b}$ \\
\hline Tumour size $>7 \mathrm{~cm}$ & T2 & T3 \\
\hline Additional tumour nodule(s) in the same lobe of the primary tumour & T4 & T3 \\
\hline Additional tumour nodule(s) in another ipsilateral lobe & M1 & T4 \\
\hline Pleural dissemination (malignant pleural effusion and separated pleural nodules) & T4 & M1a \\
\hline Intrathoracic metastases & M1 & M1a \\
\hline Extrathoracic metastases & M1 & M1b \\
\hline T2b NO MO & Stage IB & Stage IIA \\
\hline T2a N1 M0 & Stage IIB & Stage IIA \\
\hline T4 NO-N1 MO & Stage IIIB & Stage IIIA \\
\hline Small cell carcinomas & Included & $\begin{array}{l}\text { Included; use of TNM } \\
\text { favoured over "limited versus } \\
\text { extended" classification }\end{array}$ \\
\hline Broncho-pulmonary carcinoids & Excluded & Included \\
\hline
\end{tabular}


in a real case: a 76-year-old woman is found to have a nodule on the left upper lobe. Bronchoscopy and mediastinoscopy were negative. Left upper lobectomy and systematic nodal dissection were performed. At pathologic examination, the nodule was a $1.6 \mathrm{~cm}$ adenocarcinoma, but a $2 \mathrm{~mm}$ adenocarcinoma a few millimetres from the main tumour was identified. There was no nodal involvement. In this case, the tumour would be pathologically staged as pTla by primary tumour size, but the presence of an additional tumour nodule upstages it to pT3. The expected 5-yr-survival rate decreases from 77 to $28 \%$ [3]. Adjuvant therapy might even be considered for this stage IIB tumour. Well, the clinical questions are: 1) will this small nodule really affect prognosis the way the analysis of the IASLC database suggests?; and 2) is adjuvant therapy really indicated for this tumour? Intuitively, one is tempted to assume that the presence of any additional tumour nodule is a more advanced stage, but the fact is that there is no evidence to support this in a particular case. The prospective phase of the IASLC Lung Cancer Staging Project will try to answer this question by collecting detailed information on the number, size and distance from the primary tumour of the additional tumour nodule(s) in the same lobe and in other ipsilateral lobe(s) [14]. In the era of data-driven classification, this is the only way to answer such a relevant clinical question on staging. Regarding treatment, in the era of evidence-based medicine, new randomised clinical trials designed with stratification by TNM subsets will provide evidence on the best therapeutic option for these tumours. At the present time, accurate prognosis for an individual patient escapes our capacity to prognosticate. Prognosis is based on results from large numbers of patients with similar tumours. In this particular case, time will tell us whether the prognosis of this pT3 tumour, so classified by strictly following the letter of the TNM classification, will indeed have a pT3 or a pT1 prognosis. The decision to indicate adjuvant therapy requires thoughtful clinical judgement and the consideration of co-morbidity, postoperative course, extent of intraoperative lymph node assessment, serum CEA level, maximum standardised uptake value, and the presence of histopathologic features associated with worse prognosis: vascular invasion, perineural invasion or lymphatic permeation $[15,16]$. It is appropriate to emphasise that the evidence for benefit of adjuvant chemotherapy after complete resection of stage II NSCLC came from trials in which this stage was associated with $\mathrm{N} 1$ disease, not more advanced NO cases [17]. In discussing adjuvant treatment, the patient must understand the uncertainty of the prognosis and the uncertainty of the benefit of therapy. With all this information in mind, the multidisciplinary team in charge will be in the condition to decide on the convenience of administering adjuvant treatment or not.

Only seven patients out of 369 with contralateral lung nodules registered in the IASLC database underwent surgical treatment and, therefore, their tumours had a pathologic classification [5]. This reflects the generalised practice of denying surgical intervention to patients with lung cancer associated to contralateral nodules. A contralateral nodule may be a benign condition, a second primary tumour, a metastasis from the known lung cancer or a metastasis from an unknown second primary. It is important to bear in mind that to classify a lung cancer as $\mathrm{M} 1 \mathrm{a}$ by the presence of contralateral lung nodule(s), according to the letter of the TNM classification, the nodule must have been proven to be a tumour nodule. The M1 a descriptors are: separate tumour nodule(s) in a contralateral lobe; tumour with pleural nodules or malignant pleural or pericardial effusion. As in T3 and T4 by additional tumour nodule(s) in the lobe of the primary tumour and in another ipsilateral lobe(s), respectively, the key word is tumour. Not any nodule qualifies classification of a primary lung cancer as $\mathrm{T} 3, \mathrm{~T} 4$ or $\mathrm{M} 1 \mathrm{a}$, but only those that are of neoplastic nature. Even with this confirmation, if both the primary tumour and the additional tumour nodule(s) are of the same histopathological cell type, it will be difficult to determine whether they are synchronous primaries or metastases. To classify them as synchronous primaries, the pathologist must determine that they are different sub-types of the same histopathological cell type based on differences in morphology, immunohistochemistry and/or molecular studies. In the particular case of squamous cell carcinomas, they should be associated with carcinoma in situ. Additionally, there should be no evidence of mediastinal nodal metastases or of nodal metastases within a common nodal drainage [1]. Recent retrospective evidence has shown that the differences in standardised uptake value of PET scans are significantly higher in patients with second primary cancers than in those with metastases [18]. Differences in epidermal growth factor gene status may also differentiate one from the other [19]. Although these findings should be prospectively validated, they may help determine 
the probable nature of an accompanying nodule. In the particular case of contralateral nodules considered synchronous lung cancers, resection of both lesions is associated to 5 -yr survival rates of $38-63 \%$ in recently published series [20-22]. These results suggest that resection of both tumours is a therapeutic option that should not be denied to operable patients if both lesions are deemed completely resectable.

\section{MX is not used any more}

The analyses of the IASLC database provided enough evidence to separate intrathoracic (M1a) from extrathoracic (M1b) metastases [5]. In the best-staged group of tumours, the 5-yr survival rate of 771 patients with pleural dissemination was $6 \%$, which was not significantly different from the $3 \%$ of 369 patients with contralateral lung nodules. However, the 5-yr survival rate of $1 \%$ in the group of 4,350 patients with distant metastases was significantly different from the other two. Prognosis of metastases to single sites was not different, with median survival of 6 months. However, there were not enough data to analyse single versus multiple sites in any extrathoracic organ [5].

An innovation in the $M$ component of the classification was the removal of the MX category. It used to indicate that the presence of metastatic disease could not be assessed. It is now considered inappropriate, because the assessment of metastases can be based, at least, on clinical examination, which is the minimum examination any patient should have $[1,23]$.

\section{How to treat patients whose tumours are stage shifters}

The modifications in the Tand $\mathrm{M}$ components of the TNM classification originated some changes in stage grouping, with the relocation of certain TNM subsets in different stages (table 3). The result is that the stages of TNM7 better separate groups of tumours with significantly different prognosis compared with the stage grouping of TNM6. In TNM7, stage IIA is numerically larger than in TNM6, and its survival curve is properly located between those of stages IB and IIB [6]. These changes, however, already have raised questions on the optimal therapy for those tumours that changed from one stage to another. Large $\mathrm{T} 2$ tumours (T2bNOMO) have been upstaged from stage IB to stage IIA, a stage for which there is evidence that adjuvant therapy improves postoperative prognosis. However, these tumours were scantily represented in the clinical trials that provided evidence for the benefits of adjuvant chemotherapy. Should they now be treated according to the guidelines for treatment of stage IIA? The answer is they should not. As with the case of an additional tumour nodule in the same lobe of the primary tumour described above, new randomised clinical trials are needed to answer this question. Contrary to the perceptions recently reported $[24,25]$, in principle, a change in stage does not automatically mean a change in therapy [26]. Each case must be considered individually by the multidisciplinary team, assessing all possible factors in addition to tumour stage, to indicate adjuvant treatment or not.

\section{Quantification of regional lymph node involvement}

Regional nodal involvement in lung cancer is described by its absence (NO) or its presence, and the latter is further qualified by anatomic location of the involved lymph nodes, as follows. $\mathrm{N} 1$ : ipsilateral intrapulmonary, peribronchial and/ or hilar lymph nodes; N2: ipsilateral mediastinal and/or subcarinal lymph nodes; and N3: contralateral mediastinal and /or hilar, and ipsilateral and/or contralateral scalene and supraclavicular lymph nodes. These categories could be reliably validated with the IASLC data in the clinical and pathologic settings (table 4) [4]. The prognosis of nodal disease depending on the involvement of the different individual nodal stations was analysed and the result was that no nodal station had a significantly better or worse prognosis than another. However, when neighbouring nodal stations were amalgamated into nodal zones, three different prognostic groups were identified depending on the extent and location of nodal involvement: single pathologic N1 zone, with a 5 -yr survival rate of $48 \%$, had the best prognosis; multiple pathologic N1 zones and single pathologic N2 zone, with 5-yr survival rates of 35 and $34 \%$, respectively, had similar prognosis; and multiple pathologic N2 zones, with a 5 -yr survival rate of $20 \%$, had the worst prognosis. Figure 1 shows the new IASLC lymph node map with the nodal stations and newly described nodal zones [27]. For descriptive purposes, this nodal involvement was coded as N1a, N1b, N2a and N2b, respectively, but could not be used to modify the present $\mathrm{N}$ descriptors because the findings were based on a selected population of nearly 2,000 patients who had 
Table 4. Survival according to the nodal $(\mathrm{N})$ descriptors

\begin{tabular}{|c|c|c|c|c|c|c|}
\hline \multirow[t]{3}{*}{$\mathrm{N}$ category } & \multirow{2}{*}{\multicolumn{2}{|c|}{ Clinically staged tumours }} & \multicolumn{4}{|c|}{ Surgically treated patients } \\
\hline & & & \multicolumn{2}{|c|}{ Clinically staged tumours } & \multicolumn{2}{|c|}{ Pathologically staged tumours } \\
\hline & Patients n & 5 -yr survival rate $(\%)$ & Patients n & 5-yr survival rate $(\%)$ & Patients n & 5-yr survival rate $(\%)$ \\
\hline No & 19806 & 42 & 15711 & 50 & 16530 & 56 \\
\hline N3 & 3209 & $7^{\#}$ & 356 & $21^{\#}$ & 201 & $6^{\#}$ \\
\hline
\end{tabular}

undergone lung resection and detailed pathologic $N$ staging and could not be validated in the clinical setting by geographic regions or by $T$

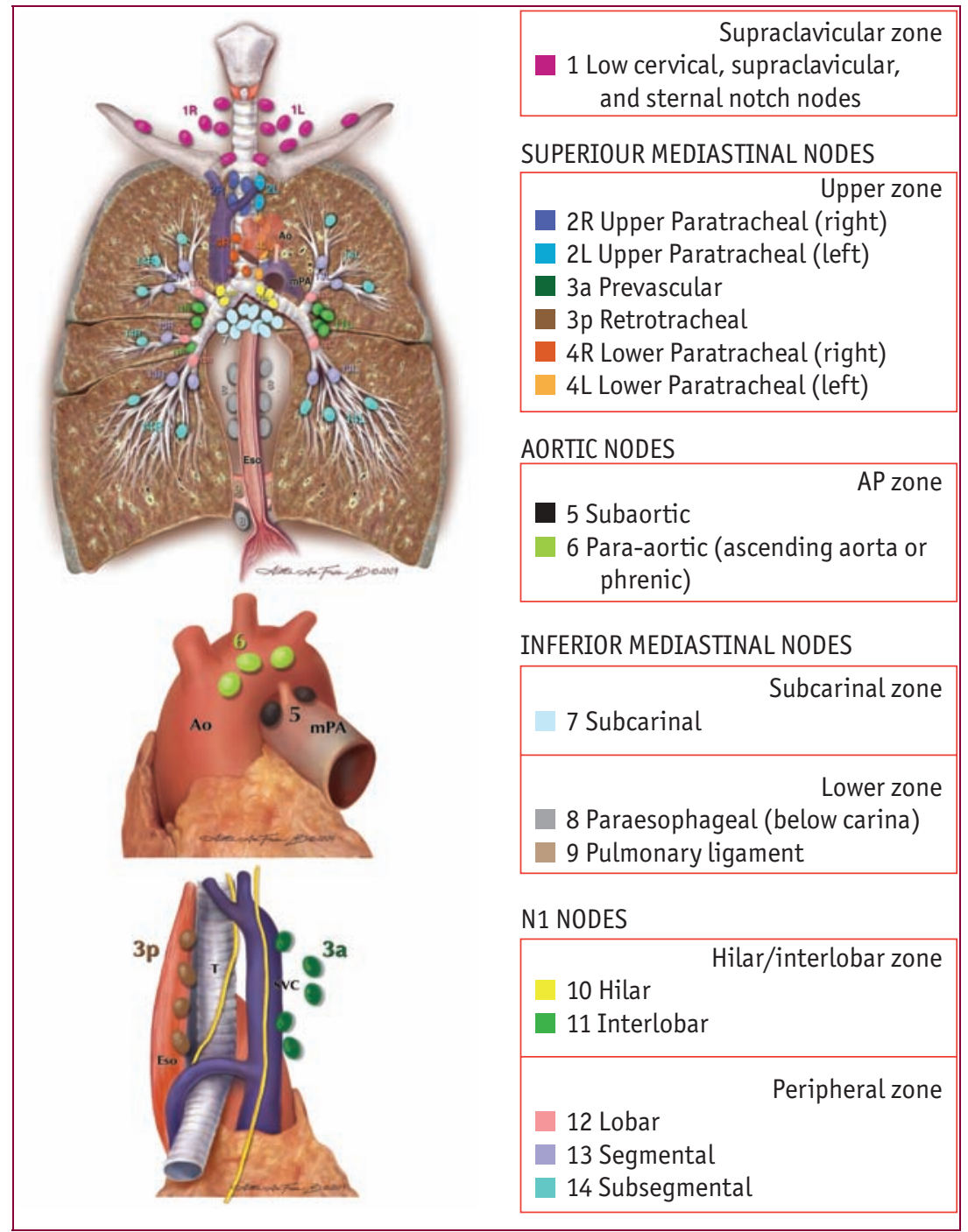

\section{Figure 1}

International Association for the Study of Lung Cancer lymph node map. Reproduced with permission from [27]. categories. If these findings could be confirmed and validated in the prospective phase of the IASLC Lung Cancer Staging Project [28], they could be used to modify the present $\mathrm{N}$ descriptors of future editions of the TNM classification of lung cancer. The innovation of this potential modification of the $\mathrm{N}$ descriptors would be that nodal involvement would be both qualified by location and quantified by number of involved nodal zones. For the time being, the findings regarding involvement of the different nodal zones can be used clinically to better assess the prognosis of those patients who underwent resection and whose tumours were found to have nodal disease.

There is a growing body of evidence that shows that the amount of tumour burden in the regional lymph nodes has prognostic impact and, therefore, clinical relevance, because it can be used to intensify follow up, adjust treatment or stratify patients in clinical trials. Nodal involvement can be quantified by the number of involved nodes [29], the number of involved lymph node stations [30-32], the number of involved lymph node zones [4, 33], and by the lymph node ratio [34], i.e., the ratio between the number of involved lymph nodes and the number of removed lymph nodes at operation. The consistent finding is that the greater the amount of involvement, the worse the prognosis. However, all these findings, although clinically relevant, derive from small singlecentre studies of pathologically staged tumours, with no clinical validation, and, therefore, more evidence and validation is needed before they can be incorporated into the TNM classification. Sooner or later, they will be incorporated, as is the case of gastrointestinal and breast cancers, among others $[11,12]$. In these tumours, the number of involved lymph nodes is an essential descriptor of the $\mathrm{N}$ component. 
Table 5. Guide to uniform classification of situations beyond the standard descriptors

\begin{tabular}{|c|c|}
\hline Situation & Classification \\
\hline Direct invasion of an adjacent lobe, across the fissure or directly if the fissure is incomplete & T2a \\
\hline Invasion of phrenic nerve & T3 \\
\hline $\begin{array}{l}\text { Paralysis of the recurrent laryngeal nerve, superior vena caval obstruction, compression of the trachea or } \\
\text { oesophagus related to lymph node involvement }\end{array}$ & N2 \\
\hline $\begin{array}{l}\text { Pancoast tumours with evidence of invasion of the vertebral body or spinal canal, encasement of the subclavian } \\
\text { vessels, or unequivocal involvement of the superior branches of the brachial plexus (C8 or above) }\end{array}$ & T4 \\
\hline Pancoast tumours without the above criteria for T4 classification & T3 \\
\hline Direct extension to parietal pericardium & T3 \\
\hline Discontinuous tumour nodules in the ipsilateral parietal or visceral pleura & M1a \\
\hline Discontinuous tumour nodules outside the parietal pleura in the chest wall or in the diaphragm & M1b \\
\hline
\end{tabular}

\section{Classification of situations beyond the standard descriptors}

There are multiple situations where the TNM rules do not fit. Over the years these have been discussed [35] and listed in the UICC supplements in order to provide guidelines for uniform use $[1,13]$. Most of these situations are described in table 5. In case of doubt, the lowest category, i.e., less advanced, should be chosen.

The classification of lymphangitis carcinomatosis has never been properly addressed in the TNM classification. Its radiographic evidence usually precludes surgical treatment, but its extent is thought to have prognostic relevance. A classification based on its radiographic extent has been proposed for prospective use and validation. It is coded as cLy and is different from the lymphatic invasion (L) descriptor, which describes invasion in the specimen (table 6). It has the following five categories [1]. cLy0: there is no radiological evidence of lymphangitis; CLy1: lymphangitis is present and confined to the area around the primary tumour; cLy2: there is evidence of lymphangitis at a distance from the primary tumour but confined to the lobe of the primary tumour; CLy3: there is evidence of lymphangitis in other ipsilateral lobes; and cLy4: lymphangitis affects the contralateral lung.

\section{Tips for a proper pathological classification}

\section{Basic requirements}

Pathological classification is based on all the information gathered to determine the clinical classification complemented with the intraoperative findings and the results of the histopathologic study of the resected specimens. It usually

\section{Table 6. Descriptors of local tumour invasiveness}

\begin{tabular}{|c|c|}
\hline \multicolumn{2}{|c|}{ L: lymphatic invasion } \\
\hline LX & Lymphatic invasion cannot be assessed \\
\hline LO & No lymphatic invasion \\
\hline L1 & Lymphatic invasion \\
\hline \multicolumn{2}{|c|}{ V: vascular (either venous or arteriolar) } \\
\hline vX & Vascular invasion cannot be assessed \\
\hline vo & No vascular invasión \\
\hline V1 & Microscopic vascular invasion \\
\hline V2 & $\begin{array}{l}\text { Macroscopic vascular invasión } \\
\text { (including involvement of the vascular } \\
\text { wall with no endovascular tumour) }\end{array}$ \\
\hline \multicolumn{2}{|c|}{ Pn: Perineural invasion } \\
\hline $\operatorname{Pn} X$ & Perineural invasion cannot be assessed \\
\hline no & No perineural invasion \\
\hline n1 & Perineural invasion \\
\hline
\end{tabular}


implies the resection of the tumour and an adequate regional lymph node assessment to establish the absence of nodal involvement (pNO). However, when the tumour cannot be resected, a pathological classification can be determined if biopsies taken during exploration can certify the highest $\mathrm{pT}$ category, for the primary tumour, or the highest $\mathrm{pN}$ category for the lymphatic spread.

The present requirements to define pNO include the histopathological examination of at least six lymph nodes/stations: three from the mediastinum, always including the subcarinal nodes, and three from hilar, peribronchial or intrapulmonary nodes. However, if the lymphadenectomy specimen includes fewer than six nodes, but all are negative, a pNO classification is also possible. However, the appropriate designation would be pNX if no lymph nodes are resected or examined [23]. The resected lymph nodes and those dissected from the lung specimen by the pathologist should be labelled according the IASLC lymph node map [27]. Direct invasion of lymph nodes by the primary tumour is classified as N1 or N2. There is evidence suggesting that this pattern of direct nodal involvement is associated with better prognosis compared with metastatic pattern, at least for $\mathrm{pN} 1$ squamous cell carcinoma [36]. However, at the moment, there is no specific descriptor to differentiate both nodal involvement patterns.

Pathological assessment of metastasis (pM) requires microscopic examination.

\section{Visceral pleura invasion}

Visceral pleura invasion, a T2 descriptor, is defined as invasion beyond its elastic layer. If the elastic layer cannot be identified with the standard haematoxylin and eosin stains, the use of elastic stains is recommended [37]. Four pleural (PL) categories to describe its pathologic extent have been proposed for prospective use and validation: PLO: tumour within the subpleural lung parenchyma or invades superficially into the pleural connective tissue beneath the elastic layer. This situation is not a $T$ descriptor and the T category should be assigned on other features; PL1: tumour invades beyond the elastic layer. This indicates visceral pleura invasion and is a T2a descriptor; PL2: tumour invades to the pleural surface. This also is visceral pleura invasion and, therefore, a T2a descriptor; and PL3: tumour invades into any component of the parietal pleura. This indicates invasion of the parietal pleura and is a T3 descriptor.

\section{Additional tumour nodules}

Differing from other organ sites, the classification of additional tumour nodules includes both those grossly recognisable and those found at microscopic examination of the specimen [1].

\section{Features of tumour invasion}

Table 6 shows optional descriptors of the TNM classification that indicate the local invasiveness of the tumour and have prognostic impact $[1,11]$. All are recognisable at pathologic examination and should be included in the definitive pathologic report.

\section{Residual tumour classification}

The residual tumour $(R)$ classification describes the presence or absence of tumour after treatment. It has four categories [1]: RX: the presence of residual tumour cannot be assessed; $\mathrm{RO}$ : no residual tumour; R1: microscopic residual tumour; and R2: macroscopic residual tumour

For surgical cases, the RO category is associated with complete resection. However, the mere absence of residual tumour does not indicate how the resection was performed. To further qualify the absence of residual disease, the IASLC proposed minimal requirements to classify a resection as complete: a) free resection margins confirmed microscopically, including the bronchial and vascular stumps, the peribronchial soft tissue, any peripheral margin close to the tumour and any additional resected specimen; b) a systematic nodal dissection or a lobe-specific systematic nodal dissection must be performed; c) there is no extracapsular tumour extension in nodes removed separately or in those at the margin of main lung specimen; and d) the highest mediastinal node removed must be negative [38].

In contraposition, an incomplete resection can be defined if any of the following conditions apply: a) there is tumour involvement of resection margins; b) there is extracapsular extension of tumour in nodes separately removed or in those at the margin of the main lung specimen; c) positive nodes have not been removed; or d) positive cytology of pleural or pericardial effusions [38].

There is an intermediate situation (uncertain resection) in which resection margins are negative and there is no evidence of residual disease, but the resection does not completely fulfil the requirements for a complete resection: a) the intraoperative nodal assessment has been 
less rigorous than the systematic nodal dissection or the lobe-specific systematic nodal dissection requires and does not contain the number of nodes recommended for complete resection; b) the highest mediastinal node removed is positive; c) there is carcinoma in situ at the bronchial margin; or d) pleural lavage cytology is positive [38]. The recommended codes for these specific situations are: $\mathrm{R} 1$ (is) for presence of carcinoma in situ at the bronchial margin; $\mathrm{R} 1(\mathrm{cy}+)$ for positive pleural lavage cytology; and RO(un) for the remaining situations qualifying for uncertain resection [1].

The $\mathrm{R}$ classification applies to the primary tumour, lymph node involvement and distant metastases [39].

\section{Special situations in the histopathologic study of lymph nodes}

When the histopathologic examination is performed on the sentinel node (sn), this is indicated after the nodal descriptor: pNX(sn), pNO(sn), and pN1-3(sn).

The presence of micrometastasis, i.e. metastases not larger than $0.2 \mathrm{~cm}$, is described by adding (mi) to the pertinent nodal descriptor: $\mathrm{N} 1$ (mi), N2(mi), or N3(mi).

The presence of isolated tumour cells (ITC; single tumour cells or clusters not larger than $0.2 \mathrm{~mm}$ ) in the lymph nodes does not qualify assigning a N1, N2 or N3 category because these cells do not usually show metastatic activity or penetration of vascular wall. However, their presence or absence has to be described and the appropriate classification depends on the method of their identification: immunohistochemistry stains (i+ or $\mathrm{i}$-) or non-morphologic techniques, such as flow cytometry or DNA analysis (mol+or mol-): NO(i-): no regional lymph node metastasis histologically, negative morphological findings for ITC; $\mathrm{NO}(i+)$ : no regional lymph node metastasis histologically, positive morphological findings for ITC; $\mathrm{NO}$ (mol-): no regional lymph node metastasis histologically, negative nonmorphological findings for ITC; $\mathrm{NO}(\mathrm{mol}+)$ : no regional lymph node metastasis histologically, positive non-morphological findings for ITC.

If the study is performed on a sentinel node, (sn) should be added: e.g. NO(i+)(sn).

\section{Isolated tumour cells in bone marrow}

This follows the same rules for nodal staging: $\mathrm{MO}(\mathrm{i}-), \mathrm{MO}(\mathrm{i}+), \mathrm{MO}(\mathrm{mol}-)$ and $\mathrm{MO}(\mathrm{mol}+$ ).

\section{Intensity and validation of the staging process}

The TNM classification does not require a minimum number of tests to determine the anatomic tumour extent. There are many tests with different accuracies and, depending on the number and type of tests used in the staging process, the resulting TNM classification can be more or less accurate. In order to homogenise the staging process, the UICC recommends the use of the certainty factor (C-factor), an optional descriptor that reflects the intensity of the studies and the validity of the classification $[1,11]$. It has five categories: $\mathrm{Cl}$ : evidence from standard diagnostic means (e.g., inspection, palpation, and standard radiography, intraluminal endoscopy for tumour of certain organs); C2: evidence obtained by special diagnostic means (e.g., radiographic imaging in special projections, tomography, computerised tomography, ultrasonography, lymphography, angiography, scintigraphy, magnetic resonance imaging, positron emission tomography, endoscopy, biopsy, and cytology); C3: evidence from surgical exploration, including biopsy and cytology; C4: evidence of the extent of disease following definitive surgery and pathological examination of the resected specimen; $\mathrm{C5}$ : evidence from autopsy.

Certainty factors C1, C2 and C3 apply to clinical classification, while C4 applies to pathologic classification.

Although this is a good way to assess the intensity of the staging process, certainty factor C2 is a mixture of anatomic and metabolic imaging, and endoscopies with or without biopsy or cytology. As more experience is gained in the clinical application of the certainty factor, C2 will have to be subdivided to describe more clearly the type of tests used, because their accuracy is not homogeneous; e.g., computerised tomography is grouped together with bronchoscopy, that can provide cytohistological prove of the primary tumour and its nodal spread if the appropriate endoscopic procedures are used.

\section{The future}

The classification of anatomic tumour extent is a strong predictor of prognosis, but it is not the only one. Prognosis of lung cancer depends on several factors related to the tumour itself, to the patient and to the environment [1], and all these are not addressed by the TNM classification. In 
the retrospective phase of the IASLC Lung Cancer Staging Project, simple parameters such as performance status, age, sex and certain laboratory tests, such as albumin, white blood tests and hypercalcaemia, were found to be significant prognostic variables $[40,41]$. In the TNM7, the stage grouping of several tumours has already been complemented with nonanatomic parameters (age, mitotic rate, histopathologic grade and location, among others), and tables combining the TNM classification with other information to produce prognostic groupings have been added to help in the assessment of prognosis. In their latest staging manuals, the UICC provides separate tables to describe stage grouping and prognostic grouping, while the AJCC combines both in the same table $[11,12]$. Sooner or later, as more information is gathered, including molecular and genetic features, this will be the case of lung cancer but, at the moment, the TNM classification of lung cancer remains to be the assessment of its anatomic extent and the strongest predictor of prognosis [40-42].

\section{Conclusion}

TNM7 better separates groups of tumours of significantly different prognosis compared with TNM6, but requires more precision in the determination of tumour size. The different $\mathrm{T}, \mathrm{N}$ and $M$ descriptors, the core of the TNM classification, are supplemented by rules and optional descriptors, that also are periodically revised, that help classify tumours in a very precise way, both in the clinical and pathological settings. Therefore, TNM7 should be incorporated into clinical practice because it better fulfils the objectives of the TNM classification.

\section{Educational questions}

1) In the 7th edition of the TNM classification, T4 tumours with no nodal involvement and no distant metastases (T4NOMO) are grouped in stage...
a) IIB
b) IIIA
c) IIIB
d) IV
e) IB

2) A 55-yr-old, current smoker man complaining of hoarseness is found to have a $2.5 \mathrm{~cm}$ peripheral lesion in the left upper lobe and a bulky nodal conglomerate in the aortopulmonary window on chest radiograph. Physical examination does not reveal any abnormality. Sputum cytology examination has been positive for malignant cells, compatible with non-small cell carcinoma. What would be the clinical classification of this tumour based on the information provided?
a) T2a N1 MO
b) $\mathrm{T} 4 \mathrm{~N} 2 \mathrm{MO}$
c) $\mathrm{T} 1 \mathrm{~b} \mathrm{~N} 2 \mathrm{MO}$
d) T4 NO MO
e) T1b N2 MX

3) A 64-yrold, current smoker man complains of persistent cough with blood-stained sputum. Physical examination is normal. Posteroanterior and lateral chest radiograph reveal a $3 \mathrm{~cm}$ mass in the right upper lobe. Computerised tomography confirms the presence of a $3.4 \times 3 \times 2.9 \mathrm{~cm}$ mass with some cavitation; enlarged $4 \mathrm{R}$ nodes of maximum shorter axis of $1.8 \mathrm{~cm}$. Bronchoscopy revealed a mass obstructing the posterior segment of the RUL. Biopsy was positive for squamous cell carcinoma. PET scan showed abnormal uptake in the RUL mass with a SUVmax of 5.6, and of 1.6 in the right inferior paratracheal nodes. Mediastinoscopy, with removal of 7 nodes from $4 \mathrm{R}, 7$ and $4 \mathrm{~L}$ stations, was negative. What is the clinical tumour classification with the information provided?
a) $\mathrm{T} 2 \mathrm{~N} 1 \mathrm{MO}$
b) $\mathrm{T} 4 \mathrm{~N} 2 \mathrm{MO}$
c) T2a NO MO
d) T3 NO MO
e) T2b NO MO 
4) The same patient as in question 3 underwent right thoracotomy. Right upper lobectomy and systematic nodal dissection were performed. At intraoperative exploration, a $1 \mathrm{~cm}$ nodule in the apical segment of the RLL was identified and removed by wedge resection. At pathologic examination, the RUL mass was diagnosed as well differentiated squamous cell carcinoma of $5.2 \mathrm{~cm}$. One centimetre anterior to the main mass, the pathologist found a $2 \mathrm{~mm}$ squamous cell carcinoma. The nodule of the RLL was diagnosed as well differentiated adenocarcinoma of $7 \mathrm{~mm}$ in greatest dimension. All removed nodes were negative, but an intrapulmonary node close to the RUL tumour was directly invaded by the tumour. What is the pathologic tumour classification with the information provided?
a) T2b NO MO
b) $\mathrm{T} 3 \mathrm{~N} 1 \mathrm{M} 1$
c) $\mathrm{T} 3 \mathrm{~N} 1 \mathrm{MO}$ and $\mathrm{T} 1 \mathrm{NO} \mathrm{MO}$
d) $\mathrm{T} 3(2) \mathrm{N} 1 \mathrm{MO}$
e) T4 N1 MO

\section{References}

1. Goldstraw P, Ed. Staging manual in thoracic oncology. Orange Park, Editorial Rx Press, 2009.

2. Goldstraw P, Crowley JJ. The International Association for the Study of Lung Cancer international staging project on lung cancer. J Thorac Oncol 2006; 1: 281-286.

3. Rami-Porta R, Ball D, Crowley J, et al. The IASLC lung cancer staging project: proposals for the revision of the T descriptors in the forthcoming (seventh) edition of the TNM classification for lung cancer. $J$ Thorac Oncol 2007; 2: 593-602.

4. Rusch VW, Crowley J, Giroux DJ, et al. The IASLC lung cancer staging project: proposals for the revision of the $\mathrm{N}$ descriptors in the forthcoming seventh edition of the TNM classifications for lung cancer. $\mathrm{J}$ Thorac Oncol 2007; 2: 603-612.

5. Postmus PE, Brambilla E, Chansky K, et al. The IASLC lung cancer staging project: proposals for revision of the M descriptors in the forthcoming (seventh) edition of the TNM classification of lung cancer. J Thorac Oncol 2007; 2: 686-693.

6. Goldstraw P, Crowley J, Chansky K, et al. The IASLC lung cancer staging project: proposals for the revision of the TNM stage groupings in the forthcoming (seventh) edition of the TNM classification of malignant tumours. J Thorac Oncol 2007; 2: 706-714.

7. Shepherd FA, Crowley J, Van Houtte P, et al. The International Association for the Study of Lung Cancer lung cancer staging project: proposals regarding the clinical staging of small cell lung cancer in the forthcoming (seventh) edition of the tumor, node, metastasis classification for lung cancer. J Thorac Oncol 2007; 2: 1067-1077.

8. Vallières E, Shepherd FA, Crowley J, et al. The IASLC lung cancer staging project. Proposals regarding the relevance of the TNM in the pathologic staging of small cell lung cancer in the forthcoming (seventh) edition of the TNM classification for lung cancer. J Thorac Oncol 2009; 4: 1049-1059.

9. Travis WD, Giroux DJ, Chansky K, et al. The IASLC lung cancer project: proposals for the inclusion of bronchopulmonary carcinoid tumors in the forthcoming (seventh) edition of the TNM classification for lung cancer. J Thorac Oncol 2008; 3: 1213-1223.

10. Groome PA, Bolejack V, Crowley JJ, et al. The IASLC lung cancer staging project: validation of the proposals for revision of the $\mathrm{T}, \mathrm{N}$, and $\mathrm{M}$ descriptors and consequent stage groupings in the forthcoming (seventh) edition of the TNM classification of malignant tumours. J Thorac Oncol 2007; 2: 694-705.

11. Sobin L, Gospodarowicz M, Wittekind C, Eds. TNM classification of malignant tumours. 7th edition. Oxford, WileyBlackwell, 2009; pp. 138-146.

12. Edge SB, Byrd DR, Compton CC, et al. Eds. Cancer staging manual. 7th edition. New York, Springer, 2010; pp. 253-270.

13. Wittekind Ch, Greene FL, Henson DE, et al. International Union Against Cancer TNM Supplement. A commentary on uniform use. Third edn. New York, Wiley-Liss, 2003; p. 162.

14. Giroux DJ, Rami-Porta R, Chansky K, et al. The IASLC lung cancer staging project. Data elements for the prospective project. J Thorac Oncol 2009; 4: 679-683.

15. Horn L, Sandler AB, Putnam JB Jr, Johnson DH. The rationale for adjuvant chemotherapy in stage I non-small cell lung cancer. J Thorac Oncol 2007; 2: 377-383.

16. Berghmans T, Dusart M, Paesmans M, et al. Primary tumor standardized uptake value (SUVmax) measured on flourodeoxyglucose positron emission tomography (FDG-PET) is of prognostic value for survival in non-small cell lung cancer (NSCLC). A systematic review and meta-analysis (MA) by the European Lung Cancer Working Party for the IASLC Lung Cancer Staging Project. J Thorac Oncol 2008; 3: 6-12.

17. Pignon JP, Tribodet H, Scagliotti GV, et al. Lung Adjuvant Cisplatin Evaluation: a pooled analysis by the LACE Collaborative Group. J Clin Oncol 2008; 26: 3552-3559.

18. Dijkman BG, Schuurbiers OC, Vriens D, et al. The role of ${ }^{18} \mathrm{~F}$-FDG PET in the differentiation between lung metastases and synchronous second primary lung tumours. Eur J Nucl Med Mol Imaging 2010; 37: 2037-2047.

19. Takuma T, Tanaka F, Yoneda K, et al. Diagnosis of synchronous primary lung adenocarcinomas based on epidermal growth factor (EGFR) gene status: a case report. Lung Cancer 2010; 68: 490-500.

20. De Leyn P, Moons J, Vansteenkiste J, et al. Survival after resection of synchronous bilateral lung cancer. Eur J Cardiothorac Surg 2008; 34: 1215-1222. 
21. Voltolini L, Rapicetta C, Luzzi L, et al. Surgical treatment of synchronous multiple lung cancer located in a different lobe or lung: high survival in node-negative subgroup. Eur J Cardiothorac Surg 2010; 37: 1198-1204.

22. Kocaturk CI, Gunluoglu MZ, Canserver L, et al. Survival and prognostic factors in surgically resected synchronous multiple primary lung cancers. Eur J Cardiothorac Surg 2011; 39: 160-166.

23. Greene FL, Brierley J, O'Sullivan B, et al. On the use and abuse of X in the TNM classification. Cancer 2005; 103: 647-649.

24. Boffa D, Detterbeck F, Smith EJ, et al. Should the 7th edition of the lung cancer stage classification system change treatment algorithms in non-small cell lung cancer? J Thorac Oncol 2010; 5: 1779-1783.

25. Boffa DJ, Greene FL. Reacting to changes in staging designations in the 7th edition of the AJCC staging manual. Ann Surg Oncol 2011; 18: 1-3.

26. Vansteenkiste JF, Shepherd FA. The seventh tumor, node, metastasis staging system and lung cancer treatment choices. A matter of would, could, and should. J Thorac Oncol 2010; 5: 1724-1725.

27. Rusch VW, Asamura $\mathrm{H}$, Watanabe $\mathrm{H}$, et al. The IASLC lung cancer staging project. A proposal for a new international lymph node map in the forthcoming seventh edition of the TNM classification for lung cancer. J Thorac Oncol 2009; 4: $568-577$.

28. Giroux DJ, Rami-Porta R, Chansky K, et al. The IASLC lung cancer staging project. Data elements for the prospective project. J Thorac Oncol 2009; 4: 679-683.

29. Fukui T, Mori S, Yokoi K, et al. Significance of the number of positive lymph nodes in resected non-small cell lung cancer. J Thorac Oncol 2006; 1: 120-125.

30. Riquet M, Bagan P, Le Pimpec Barthes F, et al. Completely resected non-small cell lung cancer: reconsidering prognostic value and significance of N2 metastases. Ann Thorac Surg 2007; 84: 1818-1824.

31. Kang CH, Ra YJ, Kim YT, et al. The impact of multiple metastatic nodal stations on survival in patients with resectable N1 and N2 nonsmall-cell lung cancer. Ann Thorac Surg 2008; 86: 1092-1097.

32. Misthos P, Sepsas E, Kokotsakis J, et al. The significance of one-station N2 disease in the prognosis of patients with nonsmall-cell lung cancer. Ann Thorac Surg 2008; 86: 1626-1631.

33. Lee JG, Lee CY, Bae MK, et al. Validity of International Association for the Study of Lung Cancer proposals for the revision of the $\mathrm{N}$ descriptors in lung cancer. J Thorac Oncol 2008; 3: 1421-1426.

34. Bria E, Milella M, Sperduti I, et al. A novel clinical prognostic score incorporating the number of resected lymphnodes to predict recurrence and survival in non-small-cell lung cancer. Lung Cancer 2009; 66: 365-371.

35. Mountain CF, Libshitz HI, Hermes KE, Lung cancer. A handbook for staging, imaging, and lymph node classification. Houston: Charles P Young Company, 1999.

36. Nakao M, Yoshida J, Ishii G, et al. Prognostic impact of node involvement pattern in pulmonary pN1 squamous cell carcinoma patients. J Thorac Oncol 2010; 5: 504-509.

37. Travis WD, Brambilla E, Rami-Porta R, et al. Visceral pleural invasion: pathologic criteria and use of elastic stains. Proposal for the 7th edition of the TNM classification for lung cancer. J Thorac Oncol 2008; 3: 1384-1390.

38. Rami-Porta R, Wittekind C, Goldstraw P. Complete resection in lung cancer surgery: proposed definition. Lung Cancer 2005; 49: 25-33.

39. Wittekind C, Compton C, Quirke P, et al. A uniform residual tumor (R) classification. Cancer 2009; 115: 3483-3488.

40. Sculier JP, Chansky K, Crowley JJ, et al. The impact of additional prognostic factors on survival and their relationship with the anatomical extent of disease expressed by the 6th edition of the TNM classification of malignant tumors and the proposals for the 7th edition. J Thorac Oncol 2008; 3: 457-466.

41. Chansky K, Sculier JP, Crowley JJ, et al. The International Association for the Study of Lung Cancer staging project. Prognostic factors and pathologic TNM stage in surgically managed non-small cell lung cancer. $J$ Thorac Oncol 2009; 4: 792-801.

sıәмsue pә7sә66ns

42. López-Encuentra A, López-Ríos F, Conde $E$, et al. Composite anatomical-clinical-molecular prognostic model in nonsmall cel lung cancer. Eur Respir J 2011; 37: 136-142. 